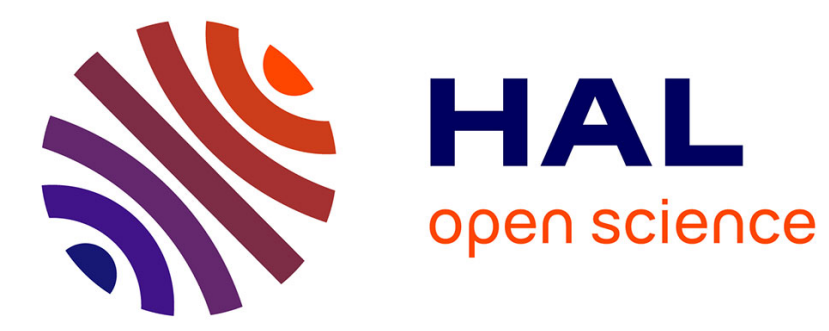

\title{
A finite-strain model for an explosive simulant
}

\author{
H. Trumel, A. Dragon, A. Fanget
}

\section{To cite this version:}

H. Trumel, A. Dragon, A. Fanget. A finite-strain model for an explosive simulant. Journal de Physique IV Proceedings, 1994, 04 (C8), pp.C8-559-C8-564. 10.1051/jp4:1994887 . jpa-00253448

\section{HAL Id: jpa-00253448 https://hal.science/jpa-00253448}

Submitted on 1 Jan 1994

HAL is a multi-disciplinary open access archive for the deposit and dissemination of scientific research documents, whether they are published or not. The documents may come from teaching and research institutions in France or abroad, or from public or private research centers.
L'archive ouverte pluridisciplinaire HAL, est destinée au dépôt et à la diffusion de documents scientifiques de niveau recherche, publiés ou non, émanant des établissements d'enseignement et de recherche français ou étrangers, des laboratoires publics ou privés. 


\title{
A finite-strain model for an explosive simulant
}

\author{
H. Trumel, A. Dragon* and A. Fanget
}

Délégation Générale pour l'Armement, Centre d'Etudes de Gramat, 46500 Gramat, France

* Laboratoire de Mécanique et de Physique des Matériaux, URA 863 du CNRS, ENSMA, Site

du Futuroscope, Chasseneuil-du-Poitou, BP. 109, 86960 Futuroscope cedex, France

\begin{abstract}
Résumé : On propose un modèle de comportement isotherme en transformations finies pour l'équivalent inerte d'un explosif. Il décrit les processus dissipatifs correspondant à deux mécanismes différents dont l'un est plastique avec dilatance et l'autre est de type viscoélastique. Ce modèle est ensuite implanté dans le code EPIC-2 et utilisé pour simuler des expériences d'impact de plaques.
\end{abstract}

\begin{abstract}
An isothermal finite strain constitutive modelling for the mechanical behaviour of an explosive simulant is presented. It accounts for two different dissipative processes including dilatational plasticity and a complementary viscous mechanism (viscoelastic-like). This model is implemented into the EPIC-2 hydrocode and used to simulate plate impact experiments.
\end{abstract}

\section{INTRODUCTION}

The safe handling of energetic materials is more and more crucial today. One of the most puzzling problems is the bullet impact and following penetration and heating due to mechanical dissipation of impacted material, possibly up to its decomposition temperature.

The present paper is devoted to the development of a constitutive model that aims at quantifying the dissipation. For that purpose, based on a proper thermodynamic framework, complex plasticity, dilatancy, and a viscous additional effect are modelled for an isotropic explosive simulant representative of a class of modern energetic materials. The latter represent a group of particulate composites comprising high proportion of grains bound by a few percent of a polymeric binder.

\section{PHENOMENOLOGY}

The phenomenology of the deformation has been explored by several authors, see f.ex. [1,2], by means of uniaxial, hydrostatic, axisymmetric 'triaxial', quasi-static as well as dynamic tests. These tests have shown that :

- the material exhibits rubber-like elasticity in the sense that its shear modulus is approximately two magnitude orders lower than its bulk modulus ;

- large elastic as well as plastic deformations occur even at relatively small loading levels ;

- at strain rates below $10^{-1} \mathrm{~s}^{-1}$, the behaviour is elastic-plastic with strain-hardening ;

- for high confining pressures, the material compacts while for low pressures, volumetric dilatancy is observed ;

- both bulk and shear moduli are sensitive to pressure and dilatancy ; so it is for the yield stress ;

- at higher strain rates $\left(\dot{\varepsilon} \geq 1 \mathrm{~s}^{-1}\right)$, strong viscous deformation mechanisms are observed in both the elastic and plastic regimes. 
From a micromechanical viewpoint, plasticity is due to relative motion of grains, unless the pressure exceeds some critical value. At lower strain rates, debonding occurs solely provoking some softening. When the strain rate increases, a competitive damage mechanism, namely grain fragmentation, occurs.

\section{CONSTITUTIVE FORMULATION}

\subsection{Preliminaries}

Accounting for the geometry of large elastic-plastic deformations, the classical kinematic relation [3] reads :

$$
\mathrm{F}_{\mathrm{iI}}=\frac{\partial \mathrm{x}_{\mathrm{i}}}{\mathrm{X}_{\mathrm{I}}}=\mathrm{F}_{\mathrm{i} \alpha}^{(\mathrm{e})} \mathrm{F}_{\alpha \mathrm{I}}^{(\mathrm{p})}
$$

We employ here rectangular coordinates. The relative polar decompositions are

$$
F_{i I}=R_{i K} U_{K I} \quad, \quad F_{\alpha I}^{(p)}=R_{\alpha J}^{(p)} U_{J I}^{(p)}
$$

The total Lagrangian strain components $E_{\mathrm{IJ}}=\frac{1}{2}\left(\mathrm{U}_{\mathrm{IK}} \mathrm{U}_{\mathrm{KJ}}-\delta_{\mathrm{IJ}}\right)$ are chosen as observable state variables ; the internal ones are $\mathrm{E}_{\mathrm{UJ}}^{(\mathrm{p})}=\left(\ln \mathrm{U}^{(\mathrm{p})}\right)_{\mathrm{UJ}}$, and an isotropic work-hardening parameter $\Lambda$.

\subsection{Hyperelasticity}

The assumption of the existence of a thermodynamic potential (the specific free energy) leads to the following expression for the supposedly isotropic material :

$$
\rho_{0} \psi(E ; E(p), \Lambda)=\frac{1}{2}(\lambda+2 \mu) I^{2}-2 \mu I I+\ell I^{3}+m I I I+n I I I
$$

I, II and III are the invariants of the elastic strain tensor $\mathrm{H}^{(\mathrm{e})}$ referred to the relaxed intermediate pseudoconfiguration $; \mathrm{H}^{\mathrm{e}}$ is defined by :

$$
H_{\alpha \beta}^{(e)}=\sum_{a=1}^{3} h\left(\lambda_{(a)}^{(e)}\right) v_{\alpha}^{(a)} v_{\beta}^{(a)}
$$

where $\lambda_{(a)}^{(e)}$ and $v^{(a)}$ are respectively the principal values and directions of $U^{(e)}$ and the function $\mathrm{h}$ takes the form [4] :

$$
\mathrm{h}\left(\lambda_{(\mathrm{a})}^{(\mathrm{e})}\right)=\frac{1}{2 \zeta}\left(\lambda^{(\mathrm{e}) 2 \zeta}-1\right)
$$

Furthermore $\lambda, \mu, \ell, m$ and $n$ represent the elastic moduli, that depend on $I_{p}: \operatorname{tr} E^{(p)}$ via $\lambda=\lambda_{0} q\left(I_{p}\right)$ $\mu=\mu_{\mathrm{o}} \mathrm{q}\left(\mathrm{I}_{\mathrm{p}}\right) \ldots \ell=\ell_{\mathrm{o}} \mathrm{q}\left(\mathrm{I}_{\mathrm{p}}\right)$ with :

$$
q\left(I_{p}\right)=\exp \left[-\left(I_{p}+1-\xi\right) / a_{p}\right]
$$

where $\xi=\frac{\rho_{0}}{\rho_{\max }}, \rho_{\max }$ being the density of the fully compacted material.

So the plastic dilatancy $I_{p}$ provoques elastic softening and can be consequently viewed as a sort of damage variable.

The conjugate forces associated with the state variables are classically obtained by partial derivation of the potential $\psi$. The elastic Piola-Kirchoff stress $S^{(R)}$ is 


$$
S_{\mathrm{IJ}}^{(\mathrm{R})}=\mathrm{F}_{\mathrm{I} \alpha}^{(\mathrm{p})^{-1}} \mathrm{M}_{\alpha \beta}^{(\mathrm{e})} \mathrm{F}_{\mathrm{J} \beta}^{(\mathrm{p})^{-1}}
$$

with $\quad M_{\alpha \beta}^{(e)}=\sum_{a=1}^{3} h^{\prime}\left(\lambda_{(a)}^{(\mathrm{e})}\right)\left(A+B h\left(\lambda_{(a)}^{(e)}\right)\right) v_{\alpha}^{(a)} v_{\beta}^{(a)}$

where $A=\lambda I+(31+m) I^{2}, \quad B=2 \mu-(m+n) I$.

$S(R)$ is related to the Cauchy true stress by

$$
\mathrm{S}_{\mathrm{IJ}}^{(\mathrm{R})}=J \mathrm{~F}_{\mathrm{Ii}}^{-1} \sigma_{\mathrm{ij}}^{(\mathrm{R})} \mathrm{F}_{\mathrm{Jj}}^{-1} \quad \mathrm{~J}=\operatorname{det}(\mathrm{F})
$$

It has been demonstrated in [4] that $\ell$ accounts for the bulk non-linearity, and with the form given above for $h$, the constant $\zeta$ controls the dependance of the shear modulus on pressure.

\subsection{Plasticity}

The thermodynamic force associated with $E^{(p)}$ is the plastic 'stress' $S(p)$ :

$$
S_{\mathrm{IJ}}^{(\mathrm{p})}=\frac{1}{J} R_{\mathrm{Ii}}^{-1} \sigma_{\mathrm{ij}}^{(\mathrm{R})} R_{\mathrm{jJ}}+\mathrm{G}_{\mathrm{IJ}}^{(\mathrm{p})}
$$

where $R_{i J}=R_{i \alpha}^{(e)} R_{\alpha J}^{(p)}$ is the total rotation, and $G_{I J}^{(p)}=\frac{1}{a_{p}} \rho_{o} \psi \delta_{I J}$ arises from the dependence of the elastic moduli on plastic dilatancy. In addition, the hardening variable is defined by :

$$
\dot{\Lambda}=\mathrm{S}_{\mathrm{IJ}}^{\mathrm{(p)}} \dot{\mathrm{E}}_{\mathrm{JI}}^{(\mathrm{p})}
$$

where $\mathrm{S}_{\mathrm{IJ}}^{\prime(\mathrm{p})}=\mathrm{S}_{\mathrm{UJ}}^{(\mathrm{p})}-\frac{1}{3} \operatorname{tr} \mathrm{S}(\mathrm{p}) \delta_{\mathrm{IJ}}$. The conjugate force associated with $\Lambda$ is supposed negligible.

Plastic yielding is supposed to occur when the state of plastic stress reaches the yield limit defined as follows :

$$
\mathrm{f}\left(\mathrm{S}(\mathrm{p}) ; \mathrm{E}^{(\mathrm{p})}, \Lambda\right) \equiv\left[\alpha^{2}\left(\mathrm{~T}_{\mathrm{I}}-\beta_{\mathrm{I}}\right)^{2}+\left(\mathrm{T}_{\mathrm{II}}-\beta_{\mathrm{II}}\right)^{2}\right]^{1 / 2}=\kappa
$$

Here, $\mathrm{T}_{\mathrm{I}}=\mathrm{S}_{\mathrm{I}} \cos \theta+\mathrm{S}_{\mathrm{II}}^{\prime} \sin \theta ; \mathrm{T}_{\mathrm{II}}=-\mathrm{S}_{\mathrm{I}} \sin \theta+\mathrm{S}_{\mathrm{II}}^{\prime} \cos \theta$

with $\quad \mathrm{S}_{\mathrm{I}}=\mathrm{S}_{\mathrm{KK}}^{(\mathrm{p})} \quad$ and $\quad \mathrm{S}_{\mathrm{II}}^{\prime}=\left[\frac{3}{2} \mathrm{~S}_{\mathrm{IJ}}^{(\mathrm{p})} \mathrm{S}_{\mathrm{JI}}^{(\mathrm{p})}\right]^{1 / 2}$ and $\mathrm{S}_{\mathrm{IJ}}^{(\mathrm{p})}=\mathrm{S}_{\mathrm{IJ}}^{(\mathrm{p})}-\frac{1}{3} \mathrm{~S}_{\mathrm{KK}}^{(\mathrm{p})} \delta_{\mathrm{IJ}}$

$\alpha, \beta_{\mathrm{I}}, \beta_{\mathrm{II}}, \kappa$ and $\theta$ are material functions depending on $\mathrm{I}_{\mathrm{p}}$ and $\Lambda$ :

$$
\begin{aligned}
& \alpha=\alpha_{0} \frac{\mathrm{Y}_{0}}{\mathrm{Y}} \mathrm{L} \gamma_{\alpha} \quad \mathrm{Y}=\mathrm{A}_{\mathrm{c}}\left(\mathrm{I}_{\mathrm{p}}+1-\xi\right)^{\mathrm{n}_{\mathrm{c}}} \exp -\frac{\mathrm{I}_{\mathrm{p}}+1-\xi}{\mathrm{B}_{\mathrm{c}}} \\
& \beta_{\mathrm{I}}=\beta_{\mathrm{II}}^{(0)} \frac{\mathrm{Y}}{\mathrm{Y}_{\mathrm{O}}} \quad \mathrm{L}=\frac{1-\exp -\mathrm{Y} / \mathrm{Y}_{1}}{1-\exp -\mathrm{Y}_{\mathrm{o}} / \mathrm{Y}_{1}} \\
& \beta_{\mathrm{II}}=\beta_{\mathrm{II}}^{(\mathrm{o})} \mathrm{L} \quad \gamma_{\alpha}=\left(1+\frac{\Lambda}{\Lambda_{\alpha}}\right)^{\mathrm{n}_{\alpha}} \\
& \kappa=\kappa_{0} L \gamma_{K} \quad \gamma_{K}=\left(1+\frac{\Lambda}{\Lambda_{K}}\right)^{n_{K}} \\
& \theta=\theta_{0} \frac{Y_{0}}{Y} L
\end{aligned}
$$


$Y_{o}, Y_{1}, \alpha_{o}, \beta_{I}^{(o)}, \beta_{I I}^{(o)}, \kappa_{0}, \theta_{o}, A_{c}, B_{c}, n_{c}, n_{\alpha}, n_{\kappa}, \Lambda_{\alpha}, \Lambda_{\kappa}$ are material constants. Their identification is discussed in a forthcoming paper [5]. The yield surface is shown on Figure 1 ; it can undergo, when $\mathrm{I}_{\mathrm{p}}$ and $\Lambda$ vary, both translation and some deformation.

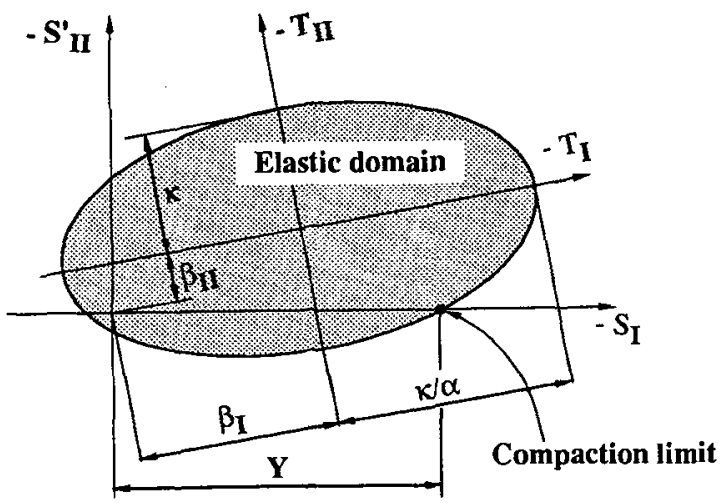

Figure 1 : Yield locus.

The yield surface form as described above appears reasonably sufficient to represent essential features, such as strength differential effect, compaction, etc. It respects the extent of the elastic range for axisymmetric 'triaxial' test paths, following some compaction.

The yield rule takes the following potential form :

$$
\dot{\mathrm{E}}_{\mathrm{UJ}}^{(\mathrm{p})}=\dot{\gamma} \frac{\partial \mathrm{g}}{\partial S_{\mathrm{IJ}}^{(\mathrm{p})}} /\left\|\frac{\partial \mathrm{g}}{\partial S_{\mathrm{JJ}}^{(\mathrm{p})}}\right\|
$$

motivated by the granular structure of the material under consideration, suggesting a non associated flow rule. The plastic potential $\mathrm{g}$ is :

$$
g=\left[\bar{\alpha}^{2}\left(S_{I}-\bar{\beta}\right)^{2}+\bar{\gamma}^{2} S_{I I}^{2}\right]^{1 / 2} \quad \text { with } \quad \bar{\beta}=\bar{b} Y
$$

and determines the direction of plastic flow. The plastic multiplier $\dot{\gamma}$ is computed by using the consistency relation :

$$
\dot{\mathrm{f}}=\dot{\mathrm{K}}
$$

\subsection{Complementary viscous mechanism}

Independently of the plastic mechanism, it is observed that a viscous additional process takes place even in the 'elastic' domain; according to the simulations performed it may contribute significantly to the total dissipation. This complementary process will be modelled in a somewhat simplified way as summarized below.

The starting point is the total stress partition into the reversible stress (5) and viscous stress $S^{(v)}$ :

$$
\mathrm{S}_{\mathrm{IJ}}=\mathrm{S}_{\mathrm{IJ}}^{(\mathrm{R})}+\mathrm{S}_{\mathrm{IJ}}^{(\mathrm{v})}
$$

$S^{(v)}$ is assumed to be related to the total deviatoric strain rate as follows :

$$
\mathrm{S}_{\mathrm{IJ}}^{(\mathrm{v})}=\mathrm{r}\left(\mathrm{J}_{2}^{\prime}\right) \mathrm{s}\left(\mathrm{II}_{\mathrm{H}}^{\prime}\right) \dot{\mathrm{E}}_{\mathrm{IJ}}^{\prime}
$$


with $\mathbf{r}$ and $s$ being material functions defined as :

$$
\begin{array}{ll}
r\left(\mathrm{~J}_{2}^{\prime}\right)=\mathrm{r}_{\text {sat }}+\left(\mathrm{r}_{\mathrm{o}}-\mathrm{r}_{\mathrm{sat}}\right) \exp \left(-\mathrm{J}_{2} / \mathrm{a}_{\mathrm{r}}\right) & \mathrm{J}_{2}^{\prime}=\left(\frac{3}{2} \operatorname{tr} \dot{\mathrm{E}}^{\prime}\right)^{1 / 2}, \dot{\mathrm{E}}^{\prime}=\dot{\mathrm{E}}-\frac{1}{3} \operatorname{tr} \dot{\mathrm{E}} 1 \\
\mathrm{~s}\left(\mathrm{II}_{\mathrm{H}}^{\prime}\right)=\mathrm{a}_{\mathrm{S}} \mathrm{II}_{\mathrm{H}}^{\prime} & \mathrm{II}_{\mathrm{H}}^{\prime}=\left(\frac{3}{2} \operatorname{tr} \mathrm{H}^{\prime}(\mathrm{e}) 2\right)^{1 / 2}, \mathrm{H}^{\prime}(\mathrm{e})=\mathrm{H}^{(\mathrm{e})}-\frac{1}{3} \operatorname{tr} \mathrm{H}^{(\mathrm{e})} 1
\end{array}
$$

Accounting for the latter viscosity mechanism, the total dissipation is :

$$
\mathrm{D}=\mathrm{S}_{\mathrm{IJ}}^{(\mathrm{p})} \dot{\mathrm{E}}_{\mathrm{J}}^{(\mathrm{p})}+\mathrm{S}_{\mathrm{IJ}}^{(\mathrm{v})} \dot{\mathrm{E}}_{\Pi}^{\prime}
$$

The first term, relative to plastic mechanism, includes the volumetric (pressure dependent) damage-like dissipation as well as the distortional one. The second, i.e. viscous term, is purely distortional. The adiabatic, approximate form of heat equation, neglecting the thermomechanical coupling, is then employed to determine the temperature rise :

$$
\rho \mathrm{C}_{\varepsilon} \dot{\mathrm{T}}=\mathrm{D}
$$

\section{ONE-DIMENSIONAL SIMULATIONS}

\begin{tabular}{|c|c|c|c|c|c|}
\hline$\rho_{0}$ & $=1835 \mathrm{~kg} \cdot \mathrm{m}^{-3}$ & $A_{c}$ & $=-4.24 .10^{8} \mathrm{~Pa}$ & & $=1$ \\
\hline$\lambda_{\mathrm{c}}$ & $=8.37 \mathrm{GPa}$ & $\mathrm{B}_{\mathrm{c}}$ & $=0.025$ & $r_{0}$ & $=6000$ Pa.s \\
\hline$\mu_{c}$ & $=20.6 \mathrm{MPa}$ & $\mathrm{n}_{\mathrm{c}}$ & $=0.047$ & $r_{\text {sat }}$ & $=1300 \mathrm{~Pa} . \mathrm{s}$ \\
\hline$\ell_{c}$ & $=-20.9 \mathrm{GPa}$ & $\mathbf{n}_{\alpha}$ & $=-0.1$ & $a_{r}$ & $=-908 s^{-1}$ \\
\hline $\mathrm{m}_{\mathrm{c}}$ & $=0$ & $\mathrm{n}_{\mathrm{K}}$ & $=1$ & $a_{s}$ & $=20$ \\
\hline $\mathrm{n}_{\mathrm{c}}$ & $=0$ & $Y_{0}$ & $=-2.42 .10^{8} \mathrm{~Pa}$ & $\mathrm{C}_{\varepsilon}$ & $=990 \mathrm{~J} \mathrm{~kg}^{-1} \mathrm{~K}^{-1}$ \\
\hline$\zeta$ & $=-0.2$ & $\mathrm{Y}_{1}$ & $=-1.88 .10^{8} \mathrm{~Pa}$ & & \\
\hline$\xi$ & $=0.981$ & $\Lambda_{\alpha}$ & $=10^{4} \mathrm{~J} \cdot \mathrm{m}^{-3}$ & & \\
\hline$a_{p}$ & $=0.0364$ & $\Lambda_{\kappa}$ & $=10^{6} \mathrm{~J} \cdot \mathrm{m}^{-3}$ & & \\
\hline$\alpha_{o}$ & $=0.0638$ & $\kappa_{0}$ & $=8.31 \mathrm{MPa}$ & & \\
\hline$\beta_{\mathrm{I}}^{(\mathrm{o})}$ & $=-1.29 .10^{8} \mathrm{~Pa}$ & $\bar{\alpha}$ & $=0.065$ & & \\
\hline$\beta_{\mathrm{II}}^{(\mathrm{o})}$ & $=-0.863 \mathrm{MPa}$ & b & $=0.9$ & & \\
\hline$\Theta_{0}$ & $=0.0135 \mathrm{rad}$ & & & & \\
\hline
\end{tabular}

The above model has been implemented into the EPIC-2 hydrocode with the set of constants assembled in Table I.

Table I : Material constants.

A symmetric plate impact experiment (impacter and target of the same material) has been simulated numerically, employing the model at stake. The free-surface velocity of impacted plate is given on Figure 2 and compared with an experimental result obtained by Cagnoux [1]. 

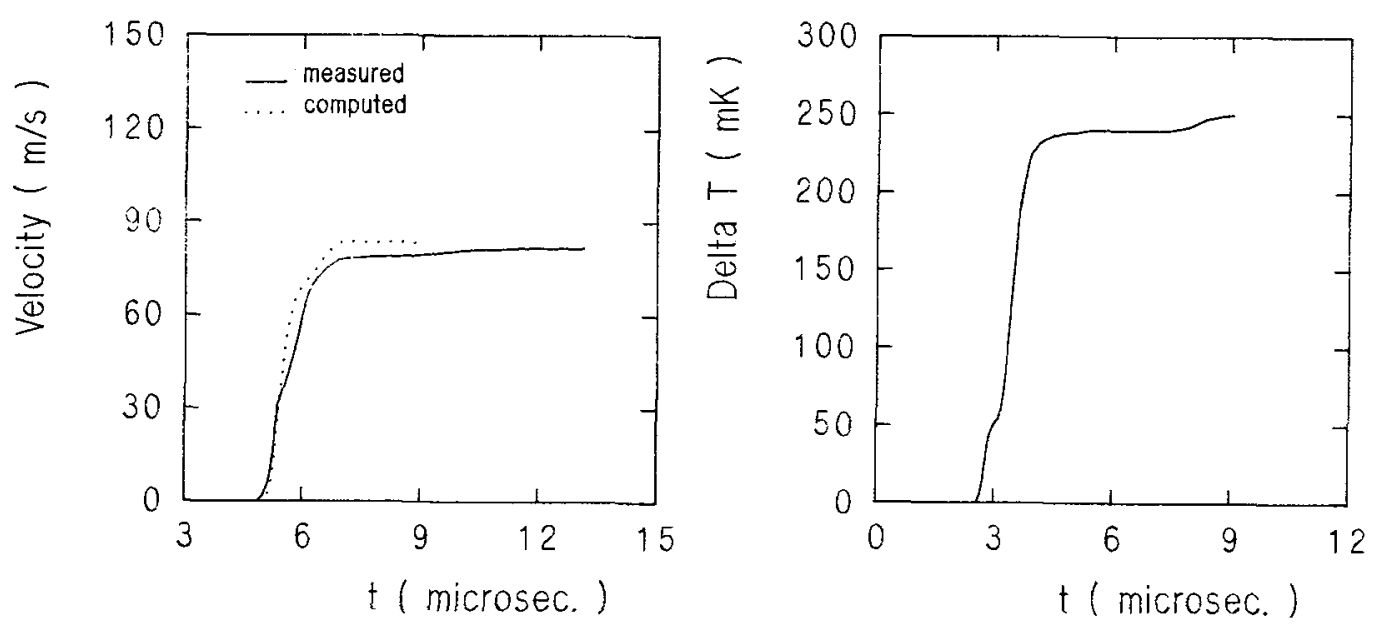

Figure 2 : Plate impact simulation (impact velocity $86 \mathrm{~ms}^{-1}$; impactor (and target) thickness : $10 \mathrm{~mm}$ ).

a) Free-surface velocity of impacted plate (simulated and experimental). b) Temperature rise (simulated).

\section{CONCLUSION}

A constitutive model for an inert explosive simulant has been developed in order to evaluate the dissipation around the projectile after a bullet impact on plastic bonded explosives. The finite strain model presented is a coupled elastic-plastic-viscous one, comprising two distinct dissipative processes relative to specific microstructural events on the grain-binder interface and within the binder itself.

The model gives reasonable predictions for salient parameters concerning the symmetric impact experiment ; a particular result is shown on Fig. 2. While some simplifications could not be avoided, preliminary predictions concerning the temperature rise in impacted specimen, though apparently very low, appear physically reasonable, see [5] for more details. The short-term perspectives of the model development include thermomechanical coupling and two-dimensional simulations.

It must be stressed that temperature predictions using a continuum model like this presented here can only yield a sort of average value for a material point (representative elementary volume). For this reason further study will concern the evaluation of spatial fluctuation of the temperature field on the microscale, i.e. accounting for heterogeneous nature of the aggregate.

\section{REFERENCES}

[1] Cagnoux J., J. de Phys., Colloque C3, Suppl. nº 9, 49 (1988) 521-528.

[2] Stankiewicz F., "Propriétés mécaniques en dynamique des explosifs composites à liant inerte", Société Nationale des Poudres et Explosifs, Rapport de recherche (1987).

[3] Lee E.H., J. Appl. Mech. 36 (1969) 1-6.

[4] Trumel H., Dragon A., Int. J. Engng Sci., in press.

[5] Trumel H., Dragon A., Fanget A., to be published. 